\title{
Morphological characterisation of Cucurbita maxima Duchesne (Cucurbitaceae) landraces from the Po Valley (Northern Italy)
}

\author{
Simone Orsenigo, ${ }^{1}$ Thomas Abeli, ${ }^{2}$ Massimo Schiavi, ${ }^{3}$ Paolo Cauzzi, ${ }^{2}$ Filippo Guzzon, ${ }^{2}$ \\ Nicola M.G. Ardenghi, ${ }^{2}$ Graziano Rossi, ${ }^{2}$ Ilda Vagge ${ }^{1}$ \\ ${ }^{1}$ Department of Agricultural and Environmental Sciences - Production, Landscape, Agroenergy, University \\ of Milan, Milan; ${ }^{2}$ Department of Earth and Environmental Sciences, University of Pavia, Pavia; \\ ${ }^{3}$ Consiglio per la Ricerca in Agricoltura e l'analisi dell'economia agraria, Centro di ricerca Genomica e \\ Bioinformatica, Montanaso Lombardo (LO), Italy
}

\begin{abstract}
Identifying crop genetic resources represent an important aspect of agricultural biodiversity conservation. However, conservation of landraces is challenging because they often cannot be properly identified, or have already suffered from genetic erosion, or have disappeared. Identification of landraces can be obtained using molecular markers or discriminating qualitative and quantitative morphological traits. The latter methodology is cheap and easily achievable, allowing the registration of landraces in national catalogues. In this study, we carried out a morphological characterisation of different accessions of Cucurbita maxima (Cucurbitaceae) cultivated in the Po Valley (N-Italy), locally known as Cappello da prete. The aim was to explore the morphological fruit variability among accessions and to identify potential distinct landraces within the Cappello da prete squash group. Differences between accessions were found indicating that morphological traits can be effectively used to identify these landraces and suggesting a diversification by isolation. Indeed, our morphological analysis shown the existence of two different landraces of
\end{abstract}

Correspondence: Filippo Guzzon, Department of Earth and Environmental Sciences, University of Pavia, via S. Epifanio 14, 27100, Pavia, Italy.

Tel.: +39.0382.984862 - Fax: +39.0382.34240

E-mail: filippo.guzzon01@universitadipavia.it

Key words: Cost-effective identification; Cucurbita maxima Duchesne; fruit morphology; landraces; morphological traits; National catalogue of conservation varieties; winter squash.

Funding: this study was funded by the project Produzione di Potenziali Varietà da Conservazione ortive ed agrarie Lombarde Registrate (V.C.L.R.) funded by Regione Lombardia PSR 2007-2013, Misura 124.

Received for publication: 13 March 2017.

Revision received: 3 January 2018.

Accepted for publication: 28 April 2018.

(C) Copyright S. Orsenigo et al., 2018

Licensee PAGEPress, Italy

Italian Journal of Agronomy 2018; 13:963

doi:10.4081/ija.2018.963

This article is distributed under the terms of the Creative Commons Attribution Noncommercial License (by-nc 4.0) which permits any noncommercial use, distribution, and reproduction in any medium, provided the original author(s) and source are credited.
Cappello da prete squashes. The adopted procedure can demonstrate that few low-cost traits are useful for the registration of local varieties in the official catalogue of landraces. Our study also demonstrates that morphological characterisation allows a rapid and cost-effective identification of diagnostic morphological traits that, together with historical and cultural information, are fundamental to recognise landraces.

\section{Introduction}

Crop landraces have significant socio-economic and heritage value; traditional local varieties represent untapped sources of genetic variability, including specific traits for pest resistance, tolerance to harsh conditions, and nutritional quality (Frankel et al., 1998). They play a key role in food security, especially in traditional and subsistence farming systems of developing countries (Brush, 1995; Louette et al., 1997), and generally in all marginal areas. Moreover, landraces have a potential economic and commercial value for niche markets (Cleveland et al., 1994; Fideghelli and Engel, 2009). Nevertheless, USA lost $95 \%$ of their landraces in the last 100 years, followed by the European Union that lost $75 \%$ of local landraces (Hammer et al., 1996; Veteläinen et al., 2009). Concerns over rapid extinction or genetic erosion of landraces resulted in widespread actions to promote their conservation. For example, the Convention on Biological Diversity (CBD) and the Global Strategy for Plant Conservation (GSPC), outline the need for agrobiodiversity conservation. The European Commission has recently approved some directives (i.e. Directive 2008/62/EC, Directive 2009/145/EC and 2010/60/EU) concerning seed trading and promoting in situ conservation and sustainable use of landraces threatened by genetic erosion. Following these Directives, EU Member States have started the registration of grain and vegetable landraces (Spataro and Negri, 2013). However, despite the growing interest of farmers and consumers in landraces, their conservation is still challenging. In many cases landraces have suffered genetic erosion caused by the replacement with modern cultivars (Srinivasan et al., 2003) or have disappeared or cannot be properly identified (de Carvalho et al., 2013), which in turn, prevent any possibility of conservation and valorisation.

Knowledge and identification of landraces can be obtained either using qualitative or quantitative morphological traits (e.g. Bidot Martinez et al., 2016) or molecular markers for investigating DNA polymorphisms (e.g. Barcaccia et al., 2016) or both (Ferriol et al., 2004). Although genetic characterisation allows unambiguous discriminations, costs and competence required are rarely affordable by individual farmers. On the contrary, morpho- 
logical characterisation is cheap, easily achievable and completely match the EU requirements for the formal registration of landraces (Directive 2008/62/EC; MIPAAF, 2012).

This is the case of the group of turban-like squashes belonging to the Cucurbita maxima Duchesne species locally known as Cappello da prete (priest's hat) and traditionally cultivated in some areas of the Po Valley (especially the provinces of Mantua, Reggio Emilia and Pavia) at least the XIX century. There is no precise information about the historical origin of Cappello da prete squashes; they are quite similar to the well-known Marina di Chioggia (another traditional cultivar from Northern Italy), characterised by a dark-green and warty epicarp. Ribbed and warty squashes already appear in paintings from the XVI and XVII centuries, although representations of turban-like forms, that can be found sometimes also in Marina di Chioggia, are unknown. The oldest written reference likely referable to Cappello da prete squashes appeared in Farneti (1892) (Marconi et al., 2012). Cappello da prete squashes have a great commercial potential as they are used for typical receipts, including the popular tortelli di zucca (a kind of stuffed pasta). However, one of the obstacle to the valorisation of these local products is the lack of formal recognition of distinct landraces within the turban-like group.

The aim of this research was therefore to explore the morphological variability among the accessions of Cappello da prete squashes from the Po Valley (Northern Italy). In particular, the identification of morphological differences among different accessions will enable low-cost (affordable by farmers) identification of landraces and will permit to understand which accession or group of accessions differ enough to be considered different landrace and worthy of being registered in the official local catalogue of landraces.

This approach, could be useful for C. maxima description/registration, as well as for the landraces of other crop species, by EU farmer communities and worldwide.

\section{Materials and methods}

\section{Plant material and measurements}

Cucurbita maxima is a partially allogamous South American species, whose first evidence of occurrence in Europe date back to the early $16^{\text {th }}$ century (Paris et al., 2006). The Turban Group, is one of the most peculiar old cultivars, with a polycarpic form, characterised by fruits (pepos) with projected carpels, and epicarp bi- or multi-coloured. It is cultivated mainly in W China and Chile, also as an ornamental cultivar (Decker-Walters and Walters, 2000; Ferriol et al., 2004; IPK Gatersleben, 2018). Cappello da prete squashes are very similar to the typical Turban squash, except for the epicarp, uniformly coloured (light grey) and always smooth. The Cappello da Prete squashes are used for human nutrition and have not any ornamental interest.

There is no precise historical information about the origin of the Italian Cappello da prete squashes, though the oldest written reference likely referable to these squashes date back to the end of the $19^{\text {th }}$ century (Farneti, 1892).

Seeds of local accessions of Cappello da prete squashes were sampled from the few custodian farmers (Gruberg et al., 2013; Sthapit et al., 2013) using self-produced seeds. Different seed accessions were stored in the Germplasm Bank of the University of Pavia. Seed of a commercial cultivar called Piacentina were purchased at the market and used as out-group. Piacentina squash was chosen as out-group because it is cultivated in the same area of the Cappello da prete squashes. Fifty seeds for each squash accessions (Piacentina, Berrettina di Lungavilla, Berrettina di Guastalla, Cappello da prete mantovana from Ostiglia and Cappello da prete mantovana from Quistello, hereafter referred as $\mathrm{PC}, \mathrm{PV}, \mathrm{RE}, \mathrm{OS}, \mathrm{MN}$, respectively) were sown in 2013 in the experimental field of CREA-ORL at Montanaso Lombardo, Lombardy, Northern Italy, under homogeneous ecological conditions. Seeds were sown every four meters in rows seven meters apart from each other at the end of May (this late sowing was due to the anomalously rainy spring 2013) and fruits were collected for morphological characterisation at the end of September. Drip irrigation was provided twice in the growing season.

Plants that reached the adult stage and produced fruits useful for the analysis varied, depending on the accession; in particular: $33,39,49,10,8$ individual plants for PC, PV, RE, OS, MN, respectively produced fruits that were measured. The following quantitative traits were measured: fruit weight, diameter and height of the upper and lower parts, number of basal lobes (projected carpels), pulp (mesocarp) and rind (epicarp) thickness, peduncle diameter, width of the placental cavity and seed weight (Figure 1). Other qualitative traits such as abundance of rind grooves, abundance of
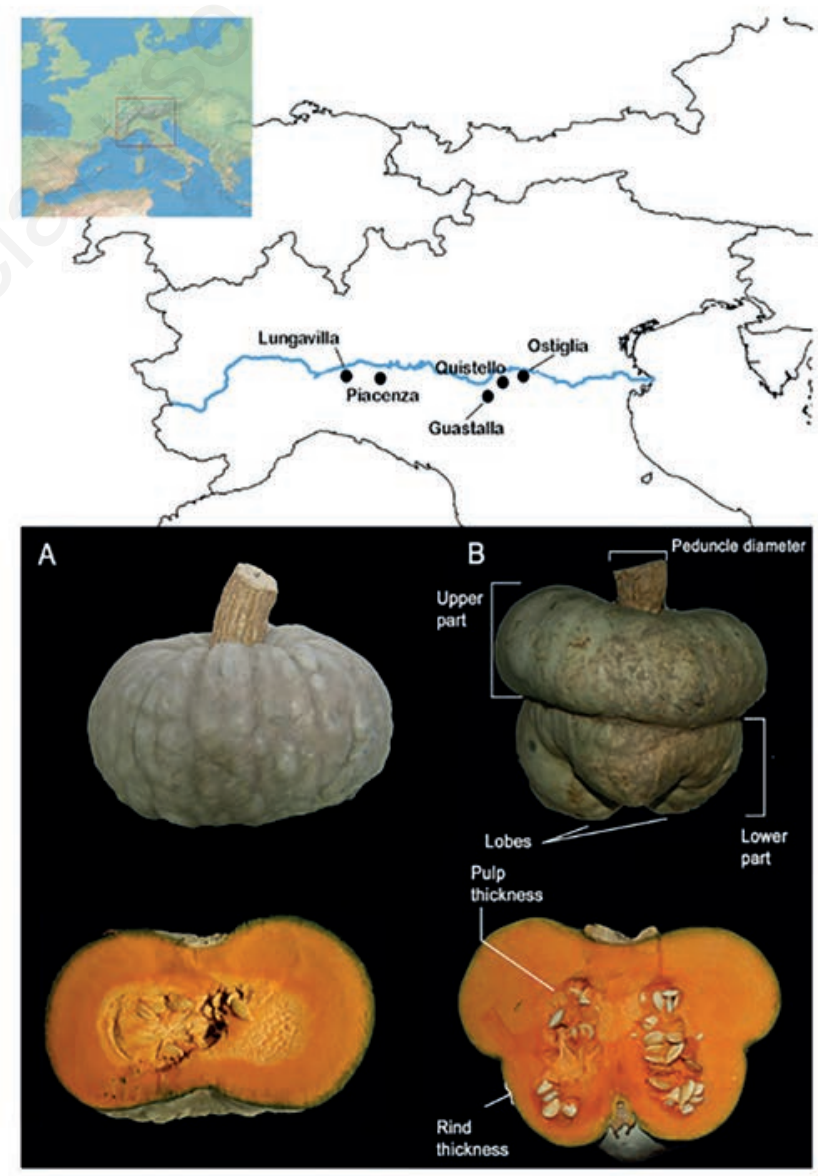

Figure 1. The higher part of the figure shows the provenance of different accessions of $C$. maxima Cappello da prete along the Po river. The lower part of the figure shows: A) Lateral view and section of the Piacentina squash; B) lateral view and section of Cappello da prete (accession MN). Some of the quantitative measurements used in the present study are shown (height of the upper and lower parts, number of basal lobes, pulp and rind thickness, peduncle diameter). 
rind dark stripes, rind rugosity and rind colour were recorded (see Supplementary material for reference fruits). For each of the above mentioned qualitative traits six reference fruits representing the variation of the total sample were selected. Fruits were assigned to one of the five categories ( 0 to 5 ), based on the comparison with the reference fruits (see Appendix S1).

\section{Statistical analysis}

Correlations between quantitative data were investigated with Spearman's correlation analysis to reduce the number of highly correlated variables from further analysis. A Spearman's Rho higher than 0.5 was used as a cut off threshold.

Quantitative and qualitative traits were analysed with a generalised linear model with accession as fixed factor. LSD pairwise comparisons were performed in case of a significant effect of accession.

\section{Results}

Spearman's correlations highlighted strong correlations between fruit weight and height of the upper part $(\mathrm{Rho}=0.934$; $\mathrm{n}=699 ; \mathrm{P}<0.001$ ), between fruit weight and diameter of the upper part $(\mathrm{Rho}=0.791 ; \mathrm{n}=697 ; \mathrm{P}<0.001)$ and between fruit weight and the size of the placental cavity $(\mathrm{Rho}=0.565 ; \mathrm{n}=697 ; \mathrm{P}<0.001)$, as well as between the number of lobes and size of the lower part ( $R h o=0.534 ; \mathrm{n}=693 ; \mathrm{P}<0.001$ ), so, among the aforementioned traits, only fruit weight and number of lobes were further used in the analysis. Other correlations were found between different traits, but not strong enough to remove such traits. Among the quantitative traits, fruit weight, pulp thickness, rind thickness, peduncle diameter and seed weight significantly differed between the squash accessions (Table 1). Differences between accessions were found for all qualitative traits, except for rind stripes.

Accession had a significant effect on all analysed traits. Pairwise comparisons shown differences for most traits between the Piacentina squash (PC) and the other Cappello da prete squashes (Figure 2; Appendix S2). These differences were expected as the Piacentina squash has a different general shape of the fruit with the lower part undeveloped. Within the group of Cappello da prete squashes, the Lungavilla squash (PV) resulted different from the other three accessions (RE, OS and MN) for many traits. Actually, PV showed unique characteristics for: fruit weight, rind and pulp thickness, peduncle diameter, rind colour and lack of rugosity, but other differences with one or the other accession were also found (Figure 2; Appendix S2). The group including RE, OS and MN shown great similarities for most traits. $\mathrm{RE}$ differed from OS for having thicker rind and pulp, bigger peduncle diameter, lower seed weight and lower rind rugosity; OS differed from MN for having smaller fruits in terms of weight and peduncle diameter, lower seed weight and less rind grooves; MN differed from RE for having larger fruits, lower number of lobes (3 and 4 , respectively), thin rind, higher seed weight, more evident rind grooves and rind rugosity (Figure 2).
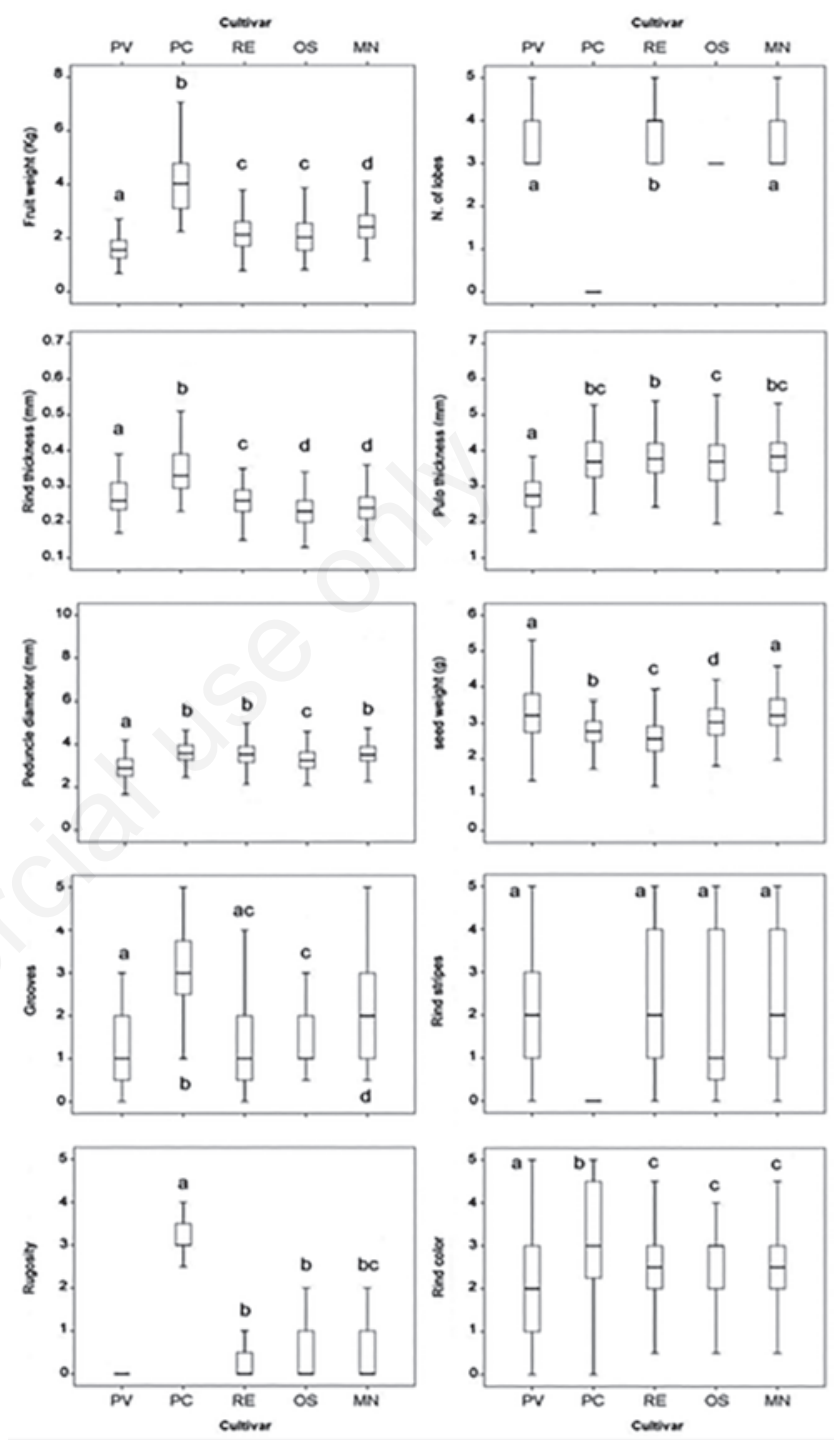

Figure 2. Results of the comparison (generalised linear model) between the Piacentina squash and four accessions of Cappello da prete squashes from Northern Italy. Different letters indicate statistically significant differences.

Table 1. Diagnostic morphological characters that allow distinguishing Piacentina from Cappello da prete mantovana and Berrettina di Lungavilla.

$$
\text { Piacentina }
$$
Cappello da prete mantovana

Rind thickness

$0.345( \pm 0.077)$

Peduncule diameter

$3.599( \pm 0.520)$

Pulp thickness

$3.766( \pm 0.833)$

Fruit weight

$4.195( \pm 1.306)$

None

$0.246( \pm 0.047)$

$3.489( \pm 0.604)$

$3.767( \pm 0.660)$

$2.262( \pm 0.704)$

From three to five




\section{Discussion}

Morphologically, Cappello da prete accessions could be easily separated from the commercial Piacentina squash (PC). Diagnostic morphological markers between accessions include the presence of lobes (from three to five), the presence of rind stripes and little to null rind rugosity. With respect to the Cappello da prete accessions, morphological data revealed significant differences between the Lungavilla squash (PV) and the other three Cappello da prete squashes (i.e. RE, OS and MN). The great similarities found in the group of RE, OS, MN when compared to PV, could be explained with the geographical proximity of their cultivation ranges. In fact, $\mathrm{RE}$, $\mathrm{OS}$ and $\mathrm{MN}$ are cultivated in suitable areas not far from each other (between 30 and $50 \mathrm{~km}$ ), while Lungavilla is cultivated in the Pavia Province as far as $150 \mathrm{~km}$ westward. It could be assumed that at the end of the $19^{\text {th }}$ century, the Cappello da prete was the most widespread group of squash cultivated along the Po River, as reported by oral sources. However, later isolation, local adaptation and unintentional selection by farmers could have favoured the selection of smaller fruits characterised by thin pulp, small peduncle and different rind colour in the westernmost accession (Figure 2).

Two main Cappello da prete landraces are therefore clearly distinguishable. They might be included in the national catalogue of MIPAAFT landraces. The first is represented by the Lungavilla, PV group (locally called Berrettina di Lungavilla), the second one is represented by eastern accessions from Reggio Emilia and Mantua provinces (locally known as Cappello da prete mantovana), which is already listed in the national catalogue (registration n. 15A01752, G.U.n. 58 11-3-2015). These two landraces are quite distinguishable even on their traditional use in their respective production areas; Cappello da prete mantovana is commonly used as stuffing for tortelli di zucca, Berrettina di Lungavilla is usually used in preparation of risotto (rice) with squash and local cakes.

Certainly, molecular data would guarantee a finer identification and clearer distinction of the accessions and relationships between Cappello da prete and Piacentina. Indeed, considering that very few studies have been carried out on C. maxima using molecular markers (Ferriol et al., 2003, 2004) and that morphological and genetic characterisation of Cucurbita revealed the presence of a high number of loci responsible for phenotypic characteristic of fruit traits (Paris and Brown, 2005), further genetic studies on the Cappello da prete landraces are needed. However, our study demonstrates that morphological characterisation, allows a rapid and cost-effective identification of diagnostic morphological traits, that together with historical and cultural information (an important aspect in landraces identification), are useful to formally recognise landraces.

\section{Conclusions}

From a socio-economic point of view, landraces can play an important role in promoting local identity and social cohesion as well as benefit the local communities, where they are cultivated. Indeed, several landraces are being rediscovered in many European Countries (Lago et al., 2015). The implementation of the European directives through the registration of landraces in national catalogues is useful to promote the conservation of landraces onfarm, which benefit the custodian farmers and increases the accessibility to traditional genetic resources (Spataro and Negri, 2013).
In this framework, as demonstrated in this study, it is important to promote cost effective and easy-way landraces identification with the final aim of favouring their registration.

\section{References}

Barcaccia G, Volpato M, Gentili R, Abeli T, Galla G, Orsenigo S, Citterio S, Sgorbati S, Rossi G, 2016. Genetic identity of common buckwheat (Fagopyrum esculentum Moench) landraces locally cultivated in the Alps. Genet. Resour. Crop Ev. 63:639-51.

Bidot Martinez I, Valdés de la Cruz M, Riera Nelson M, Bertin P, 2016. Morphological characterization of traditional cacao (Theobroma cacao L.) plants in Cuba. Genet. Resour. Crop Ev. [Epub ahead of print].

Brush SB, 1995. In situ conservation of landraces in centers of crop diversity. Crop Sci. 35:346-54.

Cleveland DA, Soleri D, Smith SE, 1994. Folk crop varieties: do they have a role in sustainable agriculture? BioSci. 44:740-51.

de Carvalho MAAP, Bebeli PJ, Bettencourt E, Costa G, Dias S, Dos Santos TMM, Slaski JJ, 2013. Cereal landraces genetic resources in worldwide GeneBanks: a review. Agron. Sustain. Dev. 33:177-203.

Decker-Walters DS, Walters TW, 2000. Squash. In: Kiple KF, Ornelas KC (Eds.), The Cambridge world history of food. Cambridge University Press, Cambridge, UK, pp 335-351.

Farneti R, 1892. Frutti freschi e secchi: Ortaggi. Fratelli Dumolard Editori, Milano, Italy.

Ferriol M, Picó B, Nuez F, 2003. Genetic diversity of some accessions of Cucurbita maxima from Spain using RAPD and SBAP markers. Genet. Resour. Crop Ev. 50:227-38.

Ferriol M, Pico B, Nuez F, 2004. Morphological and molecular diversity of a collection of Cucurbita maxima landraces. J. Am. Soc. Hortic. Sci. 129:60-9.

Fideghelli C, Engel P, 2009. Biodiversity and local genetic resources: from knowledge to exploitation. Acta Hort. 817:295-310.

Frankel OH, Brown AHD, Burdon JJ, 1998. The Conservation of Plant Biodiversity, 2nd edn. Cambridge University Press, Cambridge, UK.

Gruberg H, Meldrum G, Padulosi S, Rojas W, Pinto M, Crane TA, 2013. Towards a better understanding of custodian farmers and their roles: insights from a case study in Cachilaya, Bolivia. Bioversity International and Fundación PROINPA, Roma, Italy.

Hammer K, Knüppfer H, Xhuveli L, Perrino P, 1996. Estimating genetic erosion in landraces - two case studies. Genet. Resour. Crop Ev. 43:329-36.

IPK Gatersleben, 2018. Mansfeld's World Database of Agricultural and Horticultural Crops. Available from: http://mansfeld.ipkgatersleben.de/apex/f?p=185:3 Accessed: 15 March 2018 .

Lago C, Landoni M, Cassani E, Cantaluppi E, Doria E, Nielsen E, Giorgi A, Pilu R, 2015. Study and characterization of an ancient European flint white maize rich in anthocyanins: Millo Corvo from Galicia. PLoS One 10:e0126521.

Louette D, Charrier A, Berthaud J, 1997. In situ conservation of maize in Mexico: genetic diversity and maize seed management in a traditional community. Econ. Bot. 51:20-38.

Marconi M, Leoncini G, Pacchiarini L, 2012. Seminativi. In: Rotteglia L, Pacchiarini L (Eds.), Piante e animali dell'agrobiodiversità reggiana. Arca Regia, Reggio Emilia, Italy.

MIPAAF, 2012. Linee guida per la conservazione e la caratterizzazione della biodiversità vegetale, animale e microbica di 
interesse per l'agricoltura. Piano nazionale sulla biodiversità di interesse agricolo. Available from: https://www.reterurale.it/ flex/cm/pages/ServeBLOB.php/L/IT/IDPagina/9580

Paris HS, Brown RN, 2005. The genes of pumpkin and squash. HortSci. 40:1620-30.

Paris HS, Daunay M-C, Pitrat M, Janick J, 2006. First Known Image of Cucurbita in Europe, 1503-1508. Ann. Bot. 98:41-7.

Sthapit B, Lamers H, Rao R, 2013. Custodian farmers of agricultural biodiversity selected profiles from South and South East Asia. Proceedings of the Workshop on Custodian Farmers of Agricultural Biodiversity, 11-12 February 2013. Bioversity
International, New Delhi, India.

Spataro G, Negri V, 2013. The European seed legislation on conservation varieties: focus, implementation, present and future impact on landrace on farm conservation. Genet. Resour. Crop Evol. 60:2421-30.

Srinivasan CC, Thirtle C, Palladino P, 2003. Winter wheat in England and Wales, 1923-1995: what do indices of genetic diversity reveal? Plant Genet. Resour. 1:43-57.

Veteläinen M, Negri V, Maxted N, 2009. European landraces: onfarm conservation management and use. Biodiversity technical bullettin 15 . Biodiversity International, Rome, Italy. 